\title{
Synthesis, Fluorescence and Photoisomerization Studies of Azobenzene- Functionalized Poly(alkyl aryl ether) Dendrimers
}

\author{
Jayaraj Nithyanandhan, ${ }^{[a]}$ Narayanaswamy Jayaraman, ${ }^{[a]}$ Riju Davis, ${ }^{[b]}$ and \\ Suresh Das*[b]
}

\begin{abstract}
A series of azobenzene-functionalized poly(alkyl aryl ether) dendrimers have been synthesized and their photochemical and photophysical properties in solution and as thin films have been investigated. Although the photochemical behavior of the azodendrimers in solution indicated that the azobenzene units behave independent-
\end{abstract}

ly, very similar to the constituent monomer azobenzene unit, the properties of thin solid films of the dendrimers were distinctly different. The azoden-

Keywords: aggregation • azo compounds • dendrimers - glasses • photochemistry drimers, AzoG1, AzoG2, and AzoG3 were observed to form stable supercooled glasses, which showed longwavelength absorption and red emission characteristics of J-aggregates of the azobenzene chromophores. Reversible photoinduced isomerization of the azodendrimers in the glassy state is described.

\section{Introduction}

In the domain of macromolecules, the dendritic architecture occupies a unique place because it possesses highly regular branching units and the ability to incorporate exponentially increasing number of functional moieties in each subsequent generation. ${ }^{[1]}$ Moreover, unlike conventional macromolecules, the spatially uniform distribution of chain ends can provide a highly dense distribution of relatively disentangled functional moieties, which can extend up to nanometric structural dimensions. Recently, there has been a growing interest in the design of dendrimeric systems in which the structural features and thereby the properties, such as selfassembly, liquid crystallinity, and encapsulation, can be controlled by light. ${ }^{[2]}$ In view of this, the study of dendrimers in which photochromic molecules such as azobenzene form an integral part of the structural unit has been attracting in-

[a] J. Nithyanandhan, Dr. N. Jayaraman

Department of Organic Chemistry

Indian Institute of Science

Bangalore 560012 (India)

Fax: (+91) 80-2360-0529

E-mail: jayaraman@orgchem.iisc.ernet.in

[b] Dr. R. Davis, Dr. S. Das

Photosciences and Photonics Division

Regional Research Laboratory (CSIR)

Trivandrum-695 019 (India)

Fax: (+91) 471-2490-186

E-mail: sdaas@rediffmail.com

Supporting information for this article is available on the WWW under http://www.chemeurj.org/ or from the author. creasing attention. With few exceptions, in most of the reported studies, the photoresponsive behavior of the azo chromophores is not perturbed by incorporation into the dendrimer structure and they behave essentially as decoupled units. A comparative study of the isomerization behavior of azobenzene units, reported recently by Caminade, Majoral, and co-workers, ${ }^{[3]}$ had shown that the locations of azobenzene in a dendritic structure affect the isomerization rates, with the peripheral azobenzene units undergoing faster cis-trans isomerization than those located at the interior of the dendrimer structure. In a recent study, De Schryver and co-workers ${ }^{[4]}$ have observed that azobenzene-functionalized poly(propyleneimine) dendrimers undergo structural inversion in aqueous acidic media, resulting in the formation of micrometer-sized vesicles. The formation of these vesicles leads to an ordered arrangement of the azobenzene chromophores resulting in changes in their emission properties. Irradiation of the vesicles with $420 \mathrm{~nm}$ light resulted in significant changes in the ordering and the emission behavior of the azo chromophores. Studies by Vögtle and Balzani et al. ${ }^{[5]}$ have shown that dendrimers functionalized with cisazobenzenes act as better hosts for guest molecules than do the corresponding dendrimers containing the trans isomers. The use of such azodendrimers in holographic optical data storage has also been explored. ${ }^{[5 b]}$ A further important development is the demonstration by Advincula and co-workers, ${ }^{[6]}$ that azobenzene-functionalized PAMAM dendrimers not only phase segregate between the dendrimer region and the peripheral azobenzene region within a molecule, but also form aggregates interdigitized with azobenzene units. With the above and more reports ${ }^{[7]}$ on azobenzene-function- 
alized dendrimers, it is fairly clear that high density and uniform distributions of an azobenzene chromophore on a dendritic structure provide an ideal framework for the evaluation of the macroscopic properties in relation to the clustering of the chromophores within each molecule.

In the present work, we report a study of the behavior of azobenzene-terminated poly(alkyl aryl ether) dendrimers of 0-3 generations, containing 3, 6, 12, and 24 azobenzene units, respectively, in both solution and in the solid state. These studies provide clear evidence for the importance of dendritic structure in endowing anomalous material properties emanating from the chromophoric unit. The major findings herein include the observation that while all of the dendrimers exist as monomers in solution, they exist as aggregates and, as a consequence, exhibit fluorescence in thin solid films. We also find that while the azobenzene monomer is a thermotropic LC in its trans form, the dendrimers are nonmesogenic. We present a detailed study of the absorption, emission, and isomerization properties of these azobenzene-functionalized poly(alkyl aryl ether) dendrimers in the solution and in the solid state.

\section{Results}

Synthesis and characterization: We previously reported ${ }^{[8]}$ the synthesis of phloroglucinol-based poly(alkyl aryl ether) dendrimers of up to four generations with either O-benzyl protected or free hydroxyl group functionalities at their peripheries. Successful synthesis of these dendrimers involved repetitive reactions of O-alkylation and O-benzyl group deprotection of the phloroglucinol moieties in a divergent synthetic fashion. Free hydroxyl group containing dendrimers were used as pre-formed cores for further modification with the azobenzene groups. 4-Bromopentyloxy-4'- $n$-butylazobenzene (AzoM) (Scheme 1) served as the monomer azo- benzene unit for the functionalization of the dendrimers. The monomer AzoM was synthesized by first coupling 4-butylaniline with phenol in the presence of $\mathrm{HNO}_{2}$ at $0{ }^{\circ} \mathrm{C}$, followed by reacting the resulting 4-butyl-4'-hydroxyazobenzene with 1,5-dibromopentane in the presence of $\mathrm{K}_{2} \mathrm{CO}_{3}$. Hydroxyl group terminated 0 (G0), 1 (G1), 2 (G2), and 3 (G3) generation dendrimers, possessing 3, 6, 12, and 24 peripheral hydroxyl groups, respectively, were O-alkylated with AzoM. Multifold O-alkylation of these dendrimers was performed with a slight excess of AzoM (1.1 molar equivalents for each hydroxy group), in the presence of either $\mathrm{K}_{2} \mathrm{CO}_{3}$ or $\mathrm{Cs}_{2} \mathrm{CO}_{3}$. Upon completion of the O-alkylation, the azobenzene-functionalized dendrimers AzoG0, AzoG1 (Scheme 1), AzoG2 (Scheme 2), and AzoG3 (Scheme 3) were purified by routine column chromatography $\left(\mathrm{SiO}_{2}\right)$ and product identification was possible by TLC analysis for all the dendrimers. While the O-alkylation yields were good for zero (AzoGo) and first (AzoG1) generation dendrimers, only moderate yields could be obtained in for the second (AzoG2) and third (AzoG3) generation dendrimers. The constituent monomer AzoM and the zero generation dendrimer AzoGo exist as solids, whereas the dendrimers AzoG1, AzoG2, and AzoG3 are either low-melting solids or gummy substances at room temperature. All of these compounds are freely soluble in most organic solvents.

The structural characterization of the azobenzene-functionalized dendrimers AzoG0-AzoG3 was carried out by ${ }^{1} \mathrm{H}$ and ${ }^{13} \mathrm{C}$ NMR spectroscopy, mass spectrometry, and elemental composition analysis. General patterns of the ${ }^{1} \mathrm{H}$ NMR resonances in $\mathrm{CDCl}_{3}$ for all of the dendrimers were: i) sharp singlets for the inner and peripheral phloroglucinol units; ii) a set of double doublets of AB type spin system for the azobenzene units, and iii) doublets and triplets in the case of pentamethylene and $n$-butyl segments. The ${ }^{1} \mathrm{H}$ NMR resonances of AzoG1, AzoG2, and AzoG3 were found to be relatively broad, when compared with $\mathbf{A z o G 0}$ in $\mathrm{CDCl}_{3}$. The ${ }^{1} \mathrm{H}$ NMR spectrum of third-generation dendrimer AzoG3 is shown in Figure 1. Similarly, ${ }^{13} \mathrm{C}$ NMR spectra of the dendrimers AzoG0-AzoG3 exhibited distinct resonances corresponding to the $C$ (quat) and $\mathrm{CH}(\mathrm{me}$ thine) of phloroglucinol and those of the azobenzene units, as well as resonances for the pentamethylene and $n$-butyl linkers. The ${ }^{13} \mathrm{C}$ chemical shifts for the azobenzene unit in AzoM and in the dendrimers were nearly identical, implying the absence of any influence on the ${ }^{13} \mathrm{C}$ resonances owing to the dendritic architecture as the generations advance. Complete functionalization of the peripheries of dendrimers AzoGoAzoG2 was checked by MALDI-TOF mass spectrome-
Scheme 1. Molecular structures of the monomer (AzoM), zero (AzoGo) and first (AzoG1) generation dendrimers. 


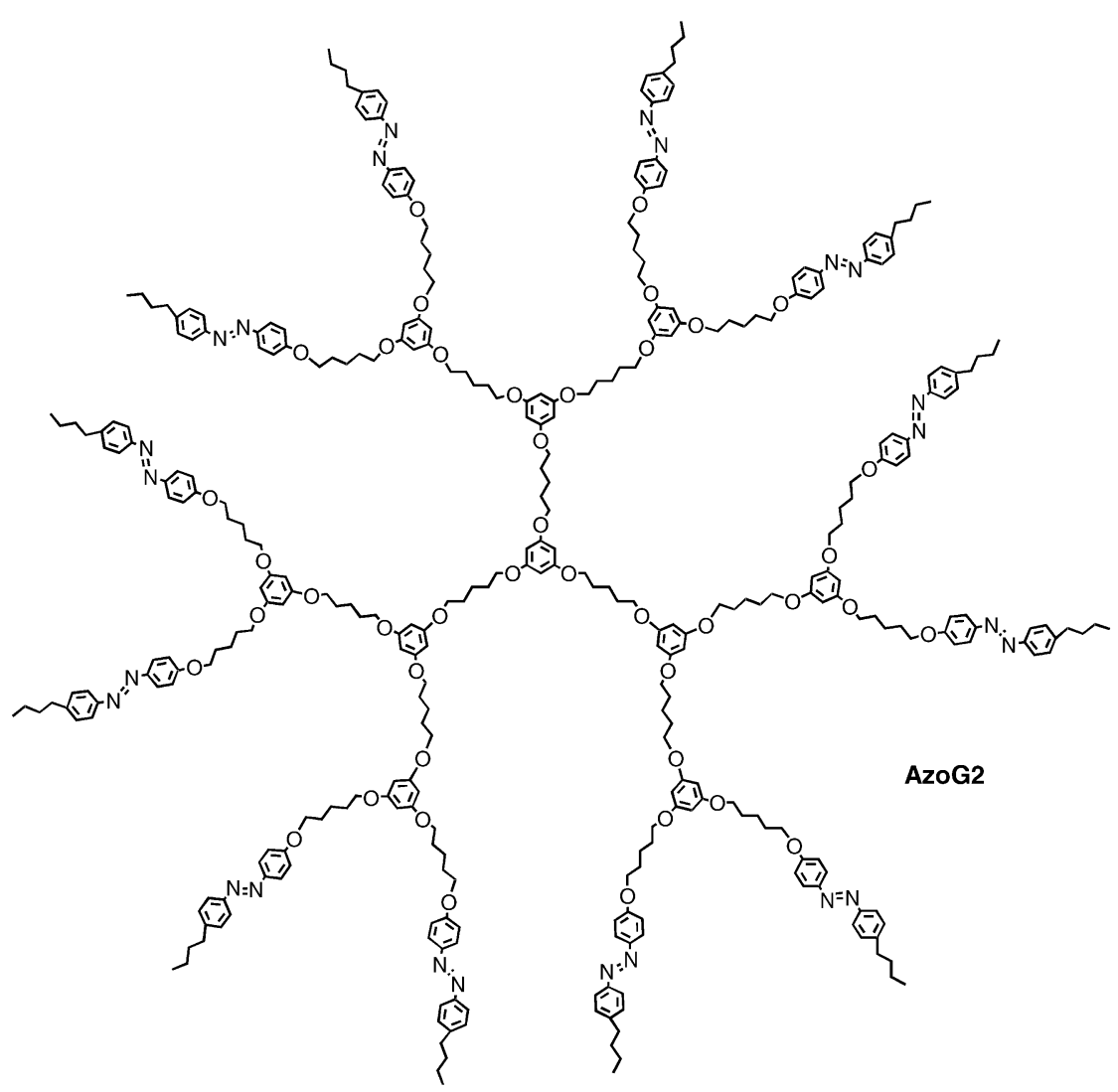

Scheme 2. Molecular structure of the second (Azo G2) generation dendrimer.

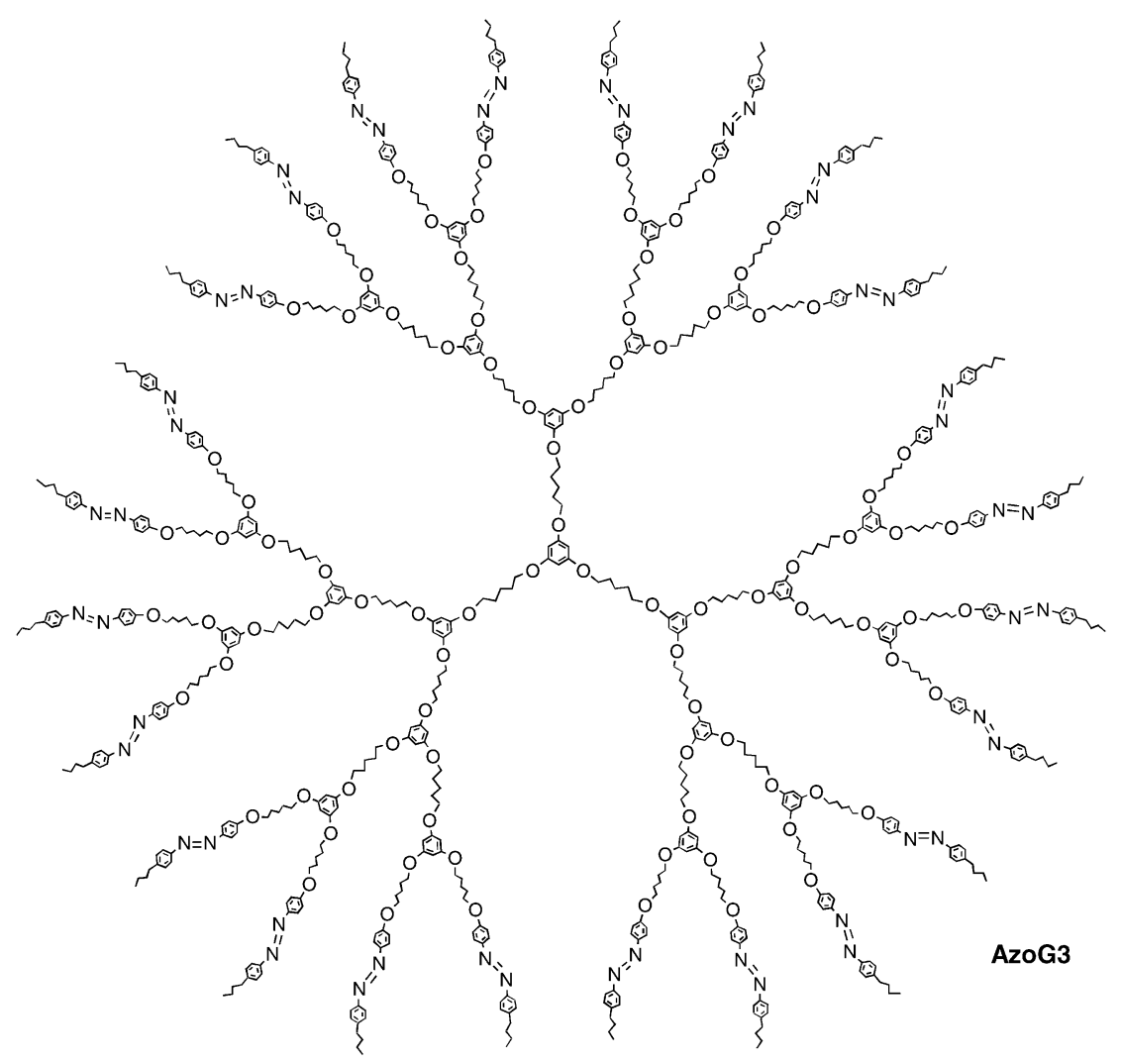

Scheme 3. Molecular structures of the third (AzoG3) generation dendrimer. try, in which the calculated molecular ion peaks were observed for each dendrimer. However, the MALDI-TOF mass spectrum of AzoG3 could not be obtained, despite repeated attempts. Elemental composition analysis could be performed so as to confirm the purities of all the azobenzene functionalized dendrimers AzoG0-AzoG3.

$\mathrm{UV} / \mathrm{Vis}$ spectrocopic characterization was performed with the monomer AzoM and the dendrimers AzoG0-AzoG3, in order to evaluate the effect of clustering azobenzene units within the dendrimer molecule. Both the $\pi-\pi^{*}$ and $\mathrm{n}-\pi^{*}$ transitions, at 350 and $450 \mathrm{~nm}$, respectively, originating from the azobenzene units ${ }^{[9]}$ were found to remain nearly identical for all the dendrimers, except that the molar extinction coefficient $(\varepsilon)$ values increase incrementally with each advancing generation. However, when calculated per azobenzene unit, the $\varepsilon$ values were nearly the same for all of the dendrimers. This indicates that the trans-azobenzene chromophores in PhMe solution are not severely affected by their attachment at the peripheries of the dendrimers. Also, in the absence of any concentration-dependent chemical shift changes in the ${ }^{1} \mathrm{H}$ NMR spectra in $\mathrm{CDCl}_{3}$, there is no intermolecular association and the dendrimers remain in their monomeric state in solution.

Material properties: Optical polarizing microscope studies of the azobenzene derivatives revealed that only the monomer AzoM exhibited liquid crystalline (LC) properties, which were characterized by the textures and sharp phase transitions observed in the heating and cooling cycles. The azobenzene monomer, AzoM exhibited a smectic $A\left(S_{A}\right)$ phase confirmed by its focal conic texture with homeotropic areas (vide infra). This was confirmed fur- 


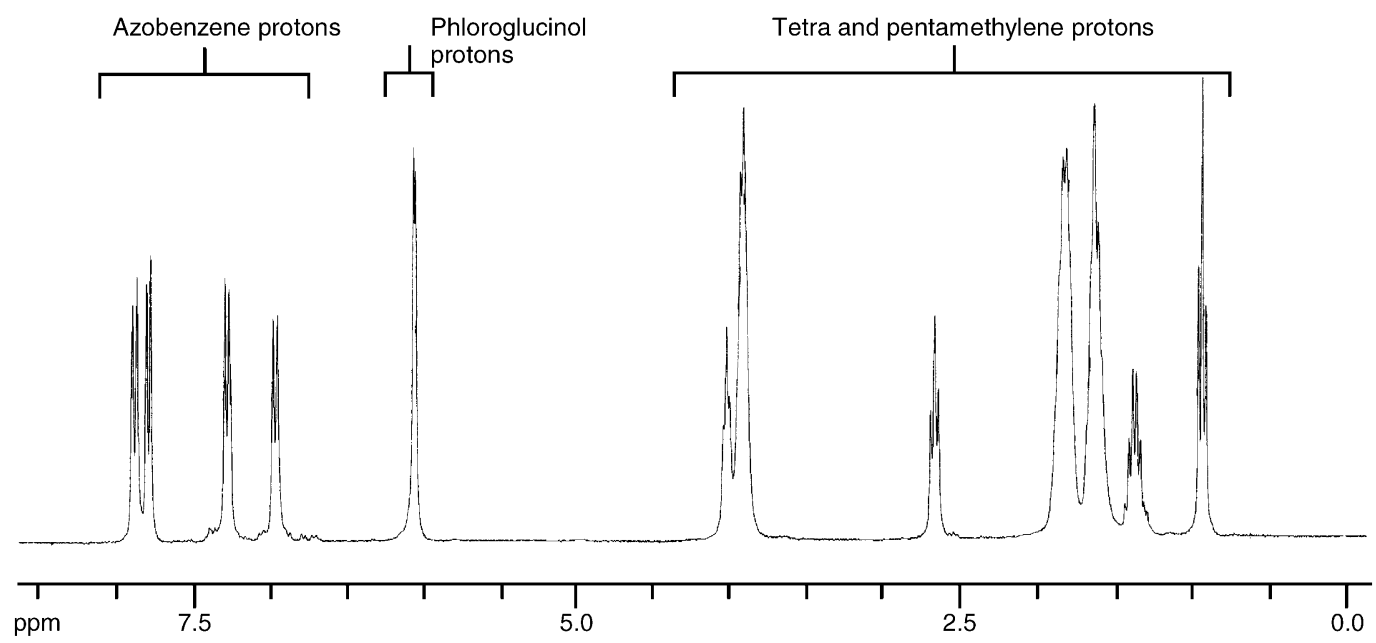

Figure 1. ${ }^{1} \mathrm{H}$ NMR spectrum of trans-AzoG3 in $\mathrm{CDCl}_{3}(300 \mathrm{MHz})$.

ther using differential scanning calorimetry (DSC) (Figure 2). Table 1 summarizes the phase transition temperatures and thermodynamic parameters of AzoM.

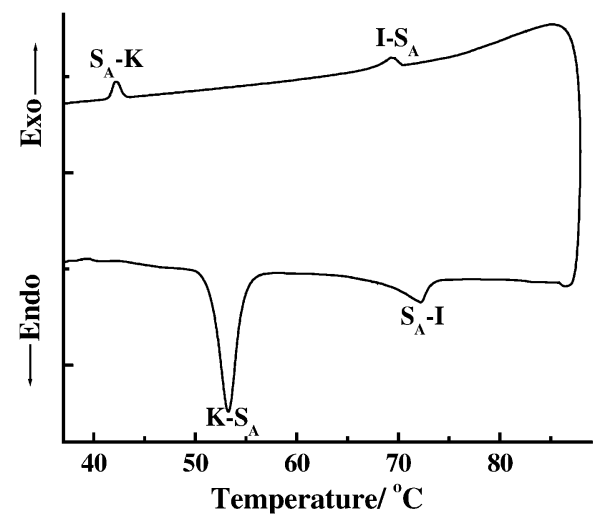

Figure 2. DSC trace of AzoM with the phase transitions indicated.

Table 1. Phase transition temperatures and thermodynamic parameters of AzoM.

\begin{tabular}{llll}
\hline Compound & $\begin{array}{l}\text { Phase transition temperatures } \\
{\left[{ }^{\circ} \mathrm{C}\right]^{\mathrm{a}]}}\end{array}$ & $\begin{array}{l}\Delta H \\
{\left[\mathrm{~kJ} \mathrm{~mol}^{-1}\right]}\end{array}$ & $\begin{array}{l}\Delta S \\
{\left[\mathrm{~J} \mathrm{~K}^{-1} \mathrm{~mol}^{-1}\right]}\end{array}$ \\
\hline AzoM & $\mathrm{K} 53.3 \mathrm{~S}_{\mathrm{A}} 72.2 \mathrm{I}$ (heating) & $20.1,4.9$ & $61.5,14.2$ \\
& $\mathrm{I} 69.5 \mathrm{~S}_{\mathrm{A}} 42.3 \mathrm{~K}$ (cooling) & $3.4,18.7$ & $9.9,59.3$ \\
\hline
\end{tabular}

[a] $\mathrm{K}=$ crystalline, $\mathrm{S}_{\mathrm{A}}=$ smectic $\mathrm{A}, \mathrm{I}=$ isotropic.

In contrast, none of the dendrimers were found to be liquid crystalline. Upon heating, dendrimers AzoG1, AzoG2, and AzoG3 melt to their isotropic states, which do not crystallize upon cooling, but rather solidify to form supercooled, transparent glassy films that were stable at room temperature for long periods ( $>6$ months). AzoGo, however, crystallizes upon cooling from its isotropic state. Junge and McGrath have also reported formation of glasses in higher order azobenzene-functionalized dendrimers. ${ }^{[7 a]}$
Solid-state absorption and emission: The absorption spectrum of a thin solid film of AzoM, formed between quartz plates by cooling from its LC state, possesses a weak absorption in the $400-500 \mathrm{~nm}$ region and a flat, more intense absorption at $\lambda<400 \mathrm{~nm}$.

The absorption spectral features of the azodendrimers were distinctly different from that of AzoM. The glassy films of AzoG1, AzoG2, and AzoG3, had absorption spectra with two clear bands with maxima centered on 355 and $440 \mathrm{~nm}$ (Figure 3). The relative intensity of the long-wavelength band is higher for the azodendrimers than that of AzoM. The absorption spectrum of AzoGo was found to be temperature dependent. Its absorption spectral changes were monitored as a function of time as it cooled from its freshly obtained melt (Figure 4). AzoGo solidifies into a glassy state from its melt and the absorption spectrum of this state is shown in Figure 4, curve a. On cooling to room temperature, the film crystallizes and the absorption spectrum of this film is shown in Figure 4, curve b. The ratio of the absorbance at $350 \mathrm{~nm}$ to that at $450 \mathrm{~nm}$ increases from 1.2 to 1.8 on going from curve a to curve $b$.

The absorption spectra of azobenzene derivatives in solution are known to have two bands with maxima centered

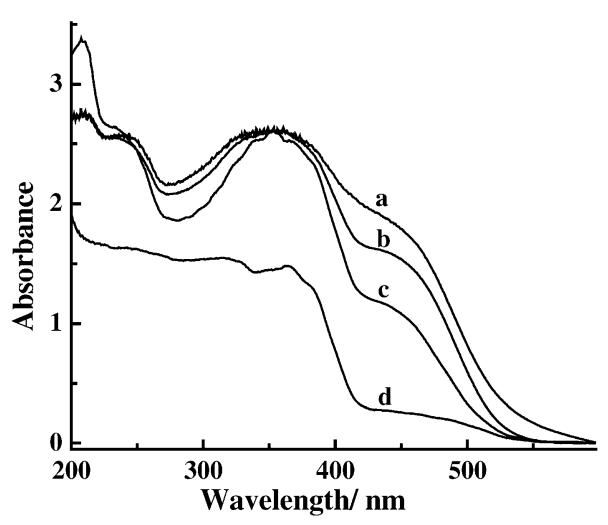

Figure 3. Absorption spectra of thin films of the azobenzene derivatives; a) AzoG1, b) AzoG3, c) AzoG2 and d) AzoM. 


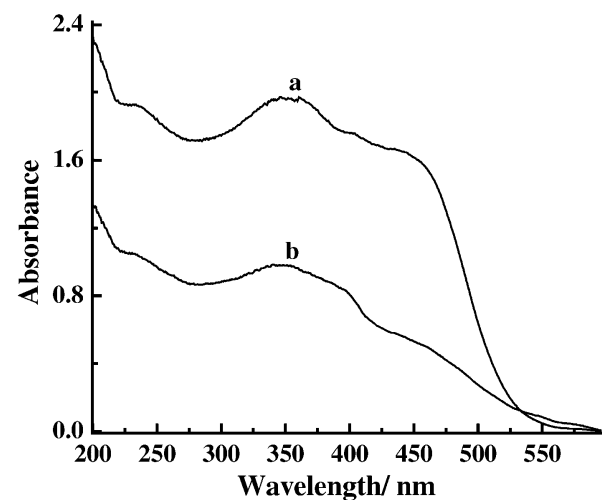

Figure 4. Absorption spectra of thin films of AzG0 a) recorded immediately after melting, b) after $2 \mathrm{~min}$.

around 350 and $450 \mathrm{~nm}$, attributed respectively to $\pi-\pi^{*}$ and $\mathrm{n}-\pi^{*}$ transitions. In the present study, the absorption of the glassy films has a broad band centered on $350 \mathrm{~nm}$ and the relative intensity of the absorption band in the $450 \mathrm{~nm}$ region is much higher than in solution. In bulk materials, the tendency to form aggregates is very high. Interaction between chromophores in their ground state on aggregation has been fairly well explained by McRae and Kasha in terms of exciton coupling theory. ${ }^{[10]}$ The excited state of aggregates is split into two energy levels (Davydov splitting). The transition to the upper state is allowed in the case of $\mathrm{H}$ aggregates, and is characterized by a hypsochromically shifted absorption band, the transition to the lower state is allowed for J-aggregates, and is marked by a bathochromically shifted absorption band compared with the isolated monomer. The higher intensity of the $450 \mathrm{~nm}$ band in the absorption spectra of the solid films of AzoG1, AzoG2, and AzoG3, compared with that in solution indicates that there could be a significant contribution to the absorption in this region by the red-shifted band associated with J-type aggregates. In AzoGo, the relative intensity of the $450 \mathrm{~nm}$ band compared with that of the $350 \mathrm{~nm}$ band is higher in the glassy state obtained from its melt than in that observed for its stable crystalline state, indicating that J-aggregate formation is enhanced in the glassy state. The broadening of the $350 \mathrm{~nm}$ band in the glassy films is also indicative of the formation of H-type aggregates.

Formation of H- and J-type aggregates has been reported in some azobenzene-containing bilayers ${ }^{[11]}$ lipids and vesicles, ${ }^{[4,12]}$ Langmuir Blodgett (LB) films, ${ }^{[13]}$ and liquid crystalline phases. ${ }^{[14]}$ Whereas the monomeric form of azobenzenes is known to be nonfluorescent, their J-aggregates are reported to fluoresce in the $600 \mathrm{~nm}$ region. ${ }^{[14 b]}$ The solid state fluorescence of these dendrimers was recorded at room temperature. Whereas the solid film of AzoM was nonfluorescent, the azodendrimers AzoG1-AzoG3 were found to be fluorescent with fluorescence maxima centered at $650 \mathrm{~nm}$. Figure 5 shows the fluorescence spectra of AzoG2 upon excitation using $450 \mathrm{~nm}$ light. Azobenzene derivatives are known to be nonfluorescent in solutions owing to their ability to undergo trans-cis photoisomerization from the excited state and also because of the $n-\pi^{*}$ character of the first excited singlet state.

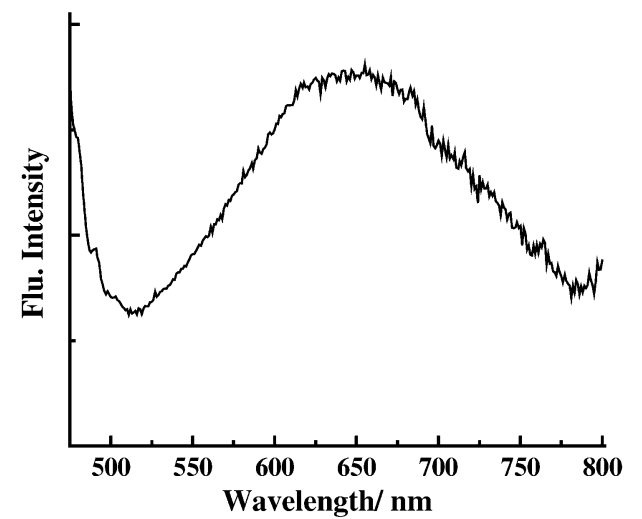

Figure 5. Solid state fluorescence spectra of a glassy film of AzoG2 upon excitation using $450 \mathrm{~nm}$ light.

The excitation spectrum of a glassy film of AzoG2, recorded while monitoring emission intensity at $650 \mathrm{~nm}$, has two maxima at about $410 \mathrm{~nm}$ and about $470 \mathrm{~nm}$ (see Supporting Information). The presence of two peaks (420 and $525 \mathrm{~nm}$ ) in the excitation spectra of azobenzene-containing bilayer membranes reported by Shimomura and Kunita$\mathrm{ke},{ }^{[11 \mathrm{~b}]}$ has been attributed to $\pi-\pi^{*}$ and $\mathrm{n}-\pi^{*}$ transitions of the J-aggregates, respectively.

Solid films of AzoG0 were found to be weakly fluorescent at room temperature in comparison to their higher order azodendrimers. As mentioned earlier, the absorption spectrum of AzoG0 showed that the formation of J-aggregates is more pronounced at temperatures close to its melting point. The fluorescence intensity of AzoGo when maintained at temperatures close to its melting point $\left(97^{\circ} \mathrm{C}\right)$ or in its isotropic state was found to be about four times higher than that at room temperature. Figure 6 shows the fluorescence spectra of AzoG0 at room temperature and at $150^{\circ} \mathrm{C}$. The

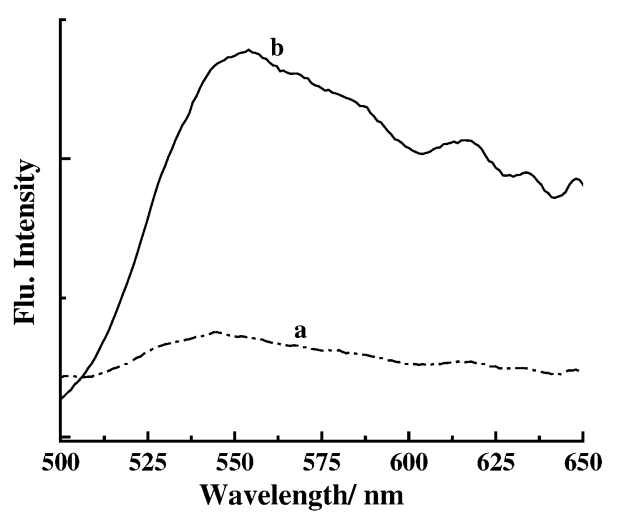

Figure 6. Solid state fluorescence spectra of AzoG0 a) solid film at room temperature, b) isotropic state maintained at $150^{\circ} \mathrm{C}$; excitation: $450 \mathrm{~nm}$.

fluorescence maximum of the J-aggregate of AzoG0 $\left(\lambda_{\max }=\right.$ $\sim 550 \mathrm{~nm}$ ) was hypsochromically shifted compared with that of the higher-order dendrimers. AzoM also shows a higher fluorescence in its isotropic and liquid crystalline phases than at room temperature in its crystalline state. 


\section{Photochemical properties:}

Photoisomerization in solution: The facile trans-cis photoisomerization and the reverse cis-trans thermal or photoisomerization are attractive features of the azobenzene chromophore in general. Isomerization of the azobenzene derivatives was followed by UV/Vis spectroscopy. Upon irradiation (300-360 nm) of a solution of each dendrimer in $\mathrm{PhMe}$ $(1.76-39.0 \mathrm{~mm})$, a drastic decrease in the absorbance of the $\pi-\pi^{*}$ transition and a slight increase in the absorbance of the $n-\pi^{*}$ transition of the azobenzene unit were observed. A photostationary state (PSS) equilibrium mixture was attained within about $5 \mathrm{~min}$ of the irradiations. On the basis of the absorbance changes, the PSS mixture was calculated to contain $85-92 \%$ of the cis isomer for each dendrimer. The thermal reversal of cis-trans isomeric form of the azobenzene unit was followed in the dark, so as to evaluate the rate constants and the activation energies associated with the isomerization process. The kinetics of thermal cis-trans isomerization were followed by time-course measurement of the absorbance changes at $350 \mathrm{~nm}$ for the photoirradiated solutions of the azobenzene derivatives at different temperatures. The isomerization followed first order kinetics in all cases as is commonly observed for azobenzene derivatives. The rate constants and the activation energies determined for this isomerization process are provided in Table 2. The

Table 2. Rate constants $(k)$ and activation energies $\left(E_{\mathrm{a}}\right)$ for thermal $c i s$ trans isomerization. ${ }^{[a]}$

\begin{tabular}{llllll}
\hline Compound & \multicolumn{5}{c}{ Rate constant $k\left[\mathrm{~s}^{-1}\right]$} \\
& at $40^{\circ} \mathrm{C}$ & $50^{\circ} \mathrm{C}$ & $60^{\circ} \mathrm{C}$ & $70^{\circ} \mathrm{C}$ & \\
\hline AzoM & $9.68 \times 10^{-5}$ & $2.72 \times 10^{-4}$ & $7.17 \times 10^{-4}$ & $1.98 \times 10^{-3}$ & 21.84 \\
AzoG0 & $9.56 \times 10^{-5}$ & $2.54 \times 10^{-4}$ & $7.56 \times 10^{-4}$ & $1.64 \times 10^{-3}$ & 20.98 \\
AzoG1 & $8.03 \times 10^{-5}$ & $2.50 \times 10^{-4}$ & $7.30 \times 10^{-4}$ & $1.83 \times 10^{-3}$ & 22.59 \\
AzoG2 & $8.22 \times 10^{-5}$ & $2.53 \times 10^{-4}$ & $6.93 \times 10^{-4}$ & $1.73 \times 10^{-3}$ & 21.66 \\
AzoG3 & $7.92 \times 10^{-5}$ & $2.54 \times 10^{-4}$ & $7.52 \times 10^{-4}$ & $1.57 \times 10^{-3}$ & 21.97 \\
\hline
\end{tabular}

[a] $k$ is expressed in $\mathrm{s}^{-1}$ and $E_{\mathrm{a}}$ in $\mathrm{kcalmol}^{-1} . E_{\mathrm{a}}$ values were obtained from the Arrhenius plot.

rate constants at different temperatures for the dendrimers were nearly the same as that of AzoM. Similarly, the activation energies $\left(E_{\mathrm{a}}\right)$ for the dendrimer series compared well with AzoM. The pre-exponential factors $(A)$, entropy and free energy changes associated with the cis-trans isomerization, and the values thus obtained from the Arrhenius plots are shown in Table 3 . The $\log A$ value of $10-11$ for the dendrimers and the monomer implies a single mechanism for the isomerization in all cases. This, in combination with the

Table 3. Activation parameters for the cis-trans isomerization in $\mathrm{PhMe}$ at $40^{\circ} \mathrm{C}$.

\begin{tabular}{llllll}
\hline Compound & $E_{\mathrm{a}}$ & $\begin{array}{l}\log \\
\end{array}$ & $\Delta G$ & $\Delta S$ & $\Delta H$ \\
& {$\left[\mathrm{kcal} \mathrm{mol}^{-1}\right]$} & {$\left[\mathrm{s}^{-1]}\right.$} & {$\left[\mathrm{kcal} \mathrm{mol}^{-1}\right]$} & {$\left[\mathrm{cal} \mathrm{mol}^{-1} \mathrm{~K}^{-1}\right]$} & {$\left[\mathrm{kcal} \mathrm{mol}^{-1}\right]$} \\
\hline AzoM & 21.84 & 11.24 & 18.33 & -9.21 & 21.22 \\
AzoGo & 20.98 & 10.63 & 16.61 & -11.99 & 20.36 \\
AzoG1 & 22.59 & 11.67 & 19.72 & -7.19 & 21.97 \\
AzoG2 & 21.66 & 11.04 & 17.87 & -10.12 & 21.04 \\
AzoG3 & 21.97 & 11.24 & 18.47 & -9.20 & -9.20 \\
\hline
\end{tabular}

$E_{a}$ values, which lie in the range of $20-22 \mathrm{kcalmol}^{-1}$, suggests an inversion mechanism for the cis-trans isomerization. Further, the activation entropies for the dendrimers are within the range close to AzoM, and these entropic values indicate that the local environments and the transition state geometries are similar for the azobenzene chromophores, regardless of their attachment to the dendritic core.

The above observations agree well with reports on various other non-push-pull type azobenzene derivatives. ${ }^{[15]}$ These solution studies also further substantiate previous observations $^{[5]}$ that the azobenzene units of azobenzene-functionalized dendrimers behave very similarly to the corresponding monomer with no steric or topological constraints.

Photoisomerization of AzoM in its liquid crystalline phase: The trans-cis photoisomerizations of chromophores have been extensively utilized in bringing about photoinduced isothermal phase transitions in liquid crystals. ${ }^{[16]}$ In liquid crystalline materials containing azobenzene chromophores as dopants or as an inherent part of the molecular structure, photoisomerization of the linear trans isomers to the bent cis isomers is known to disrupt long-range ordering, which leads to a breakdown of the liquid crystalline phases. ${ }^{[16 a]}$ Photolysis (using $360 \mathrm{~nm}$ band-pass filtered output of a $200 \mathrm{~W}$ high-pressure mercury lamp) of thin liquid crystalline films $\left(S_{A}\right)$ of AzoM, obtained by slow cooling of its isotropic state, maintained at $60^{\circ} \mathrm{C}$, resulted in an isothermal liquid crystalline to isotropic phase transition. These changes were thermally reversible. Complete thermal recovery of the initial $\mathrm{S}_{\mathrm{A}}$ phase from the isotropic state was observed at $60^{\circ} \mathrm{C}$ within 8 minutes. Within about 3 min of photolysis, domains showing the $\mathrm{S}_{\mathrm{A}}$ texture begin to appear. The optical micrographs recorded at the various stages of the isothermal phase transitions of AzoM are shown in Figure 7.
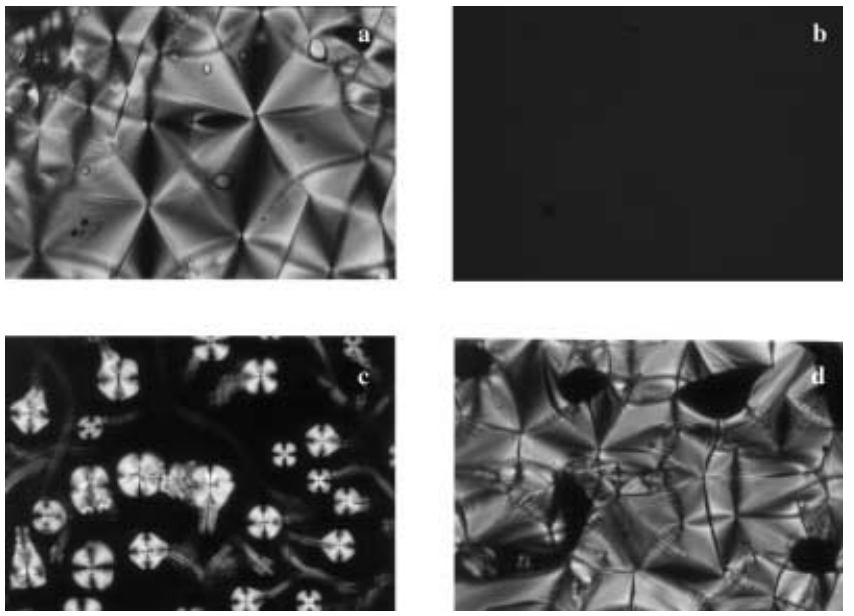

Figure 7. Polarized optical micrographs $(400 \times)$ depicting the photochemical phase transition of AzoM: a) $\mathrm{S}_{\mathrm{A}}$ phase at $60^{\circ} \mathrm{C}$ before photolysis, b) isotropic phase at $60^{\circ} \mathrm{C}$ upon photolysis using $360 \mathrm{~nm}$ light, c) homeotropic $\mathrm{S}_{\mathrm{A}}$ texture formed in $3 \mathrm{~min}$ after formation of the isotropic phase, d) focal conic $S_{A}$ texture formed in 8 minutes. 
Photoisomerization of azodendrimers in their glassy state: Photolysis of glassy films of the azodendrimers using $360 \mathrm{~nm}$ band-pass filtered output of a $200 \mathrm{~W}$ high-pressure mercury lamp did not bring about any transformation in their absorption spectra. However significant changes in their absorption spectra were observed on photolysis using the third harmonic $(355 \mathrm{~nm})$ of a Nd:YAG pulsed laser $(5 \mathrm{~mJ}$ per pulse, $10 \mathrm{~ns}$ pulse width). Figure $8 \mathrm{~A}$ shows the effect of $355 \mathrm{~nm}$ laser
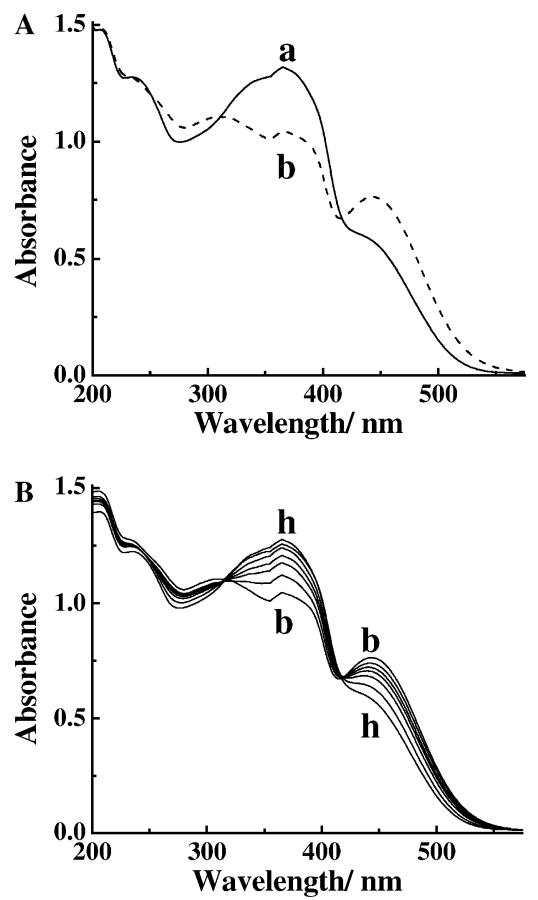

Figure 8. Absorption spectra of thin films of AzG2; A) a) glassy form; b) after photolysis using $355 \mathrm{~nm}$ laser $5 \mathrm{~mJ}$ per pulse for $30 \mathrm{~s}, \mathrm{~B}$ ) temporal change cis-trans isomerization; c) $1.6 \mathrm{~h}$; d) $3.3 \mathrm{~h}$; e) $5.0 \mathrm{~h}$; f) $8.2 \mathrm{~h}$; g) $18.2 \mathrm{~h}$; h) $74.4 \mathrm{~h}$

photolysis of a glassy film of AzoG2 for 30 s. A decrease in absorbance of the $350 \mathrm{~nm}$ band and an increase in intensity of the absorption band centered at $450 \mathrm{~nm}$ are clearly observable. The final spectrum obtained (Figure $8 \mathrm{~A}$, curve b) has an absorption maximum that is blue-shifted in comparison to that of the unphotolyzed film. At room temperature $\left(27^{\circ} \mathrm{C}\right)$, the absorption spectrum of the photolyzed film shows a slow increase in its absorbance at $350 \mathrm{~nm}$ and a concomitant decrease in the absorbance at $450 \mathrm{~nm}$; this transformation is marked by the presence of isosbestic points at 320 and $420 \mathrm{~nm}$. The changes in the absorption spectra on photolysis of the glassy films can be attributed to trans-cis photoisomerization of the azobenzene moieties followed by a slow, thermal cis-trans isomerization. The thermal cistrans isomerization occurs at a very slow rate and complete recovery is not observed even after $74 \mathrm{~h}$ (curve h, Figure $8 \mathrm{~B}$ ). The presence of isosbestic points is indicative of a single process cis-trans photoisomerization of azobenzene groups in thin glassy films.

In solution, photolysis of the azo dendrimers using $350 \mathrm{~nm}$ light results in a decrease in intensity of the $350 \mathrm{~nm}$ band and an increase in intensity of the band around $450 \mathrm{~nm}$, which is attributable to trans-cis photoisomerization. In the glassy film however the decrease in the $350 \mathrm{~nm}$ band is accompanied by a shift in the absorption maximum to $320 \mathrm{~nm}$. A similar shift in absorption maximum was observed on photolysis of azobenzene-containing dendritic monolayers. ${ }^{[13 g]}$

Heating the photolyzed sample above its glass transition temperature $\left(\mathrm{T}_{\mathrm{g}}\right)$ results in rapid cis-trans isomerization. This process of generating the cis azobenzene photochemically and thermal conversion to its trans isomer could be carried out over several cycles. Similar behavior was observed in the glassy films of AzoG1 and AzoG3.

\section{Discussion}

Azobenzene-functionalized dendrimers have been previously synthesized and studied in several instances. The most studied dendritic structures functionalized with azobenzene units at their peripheries were those derived from 1) PAMAM,${ }^{[6]} 2$ ) poly(propylene imine) ${ }^{[4,5]}$ and 3) polysilane dendrimers. ${ }^{[7 \mathrm{e}, \mathrm{f}]}$ Apart from these, azobenzene units were also incorporated at the interiors of dendritic structure such as poly(benzyl aryl ether),${ }^{[7 a-c]}$ polyphosphinated ${ }^{[3]}$ and polyphenylene dendrimers. ${ }^{[7 \mathrm{~g}]}$ Solution-phase studies reveal that the properties of the azobenzene unit, especially relating to isomerization, are highly dependent on the constituent dendrimer and the location of the azobenzene unit within the dendrimer. For example, the photoresponsive behavior of azobenzene-cored polyphenylene dendrimers is highly dependent on the dendritic structures, ${ }^{[7 \mathrm{~g}]}$ whereas such a dependence is negligible in the case of poly(benzyl aryl ether) dendrimers containing the azobenzene unit at the core. ${ }^{[7 a]}$ One of our initial goals in preparing the poly(alkyl aryl ether) dendrimers described herein was to study the role of dendritic structure, which changes periodically as a result of consecutive growth of the so-called generations, on the properties of azobenzene in the solid state and in the solution phase. Relatively little is known about the photophysical and photochemical properties azobenzene-functionalized dendrimers in the solid state. Recently Vögtle, Balzani and co-workers have shown that holographic gratings with a diffraction efficiency of $20 \%$ could be optically recorded in thin films of azobenzene-functionalized dendrimers. ${ }^{[5 b]}$ The existence of dendritic molecules as aggregates in the solid state, as evidenced from the pronounced hypsochromic shift of $\lambda_{\max }$, was previously shown by Advincula and co-workers ${ }^{[6]}$ in the case of azobenzene functionalized PAMAM dendrimers. Similar observations were also reported by Shibaev and co-workers ${ }^{[7, f]}$ for a azobenzene-functionalized first generation carbosilane dendrimer. In the present study a systematic investigation of poly(alkyl aryl ether) dendrimers AzoG1-AzoG3 show that thin solid films of these dendrimers exhibit enhanced absorption in the $450 \mathrm{~nm}$ region when compared with AzoM and AzoG0. This is indicative of the presence of J-type aggregates in the glassy films of the dendrimers. Additionally, AzoGo exhibits enhanced absorption in the $450 \mathrm{~nm}$ region in its glassy state, 
which is formed at temperatures near its melting point, indicating the formation of J-type aggregates. The corresponding solution-phase studies clearly indicate that all the compounds behave as monomers and the azobenzene units are essentially decoupled from each other. A consequence of the formation of the J-aggregate is the observed fluorescence in the glassy films of the dendrimers. Such a fluorescence property of the J-aggregate of azobenzene is reported for aqueous bilayer membranes ${ }^{[11 a, b]}$ and azobenzene liquid crystals. $^{[14 b]}$ Thus, the fluorescence emission centered at $650 \mathrm{~nm}$ observed upon excitation of the thin solid films of AzoG1-AzoG3 at $450 \mathrm{~nm}$ is attributed to the $\pi-\pi^{*}$ transition of the lower $S_{2}$ level, as rationalized by Kunitake and Shimomura for their bilayer membranes. ${ }^{[11 b]}$ With reference to azobenzene-containing dendrimers, the only known report on fluorescence involves the azobenzene-functionalized poly(propylene imine) dendrimer-derived vesicles. ${ }^{[4]}$ In contrast to these reports, the present study describes the first observation of azobenzene fluorescence exhibited by virgin solid samples of the azobenzene-functionalized dendrimers. In addtion to the room-temperature fluorescence of the dendrimers, we observe that AzoM can also be considerably fluorescent at temperatures closer to its melting point. While AzoM exhibits $\mathrm{S}_{\mathrm{m}} \mathrm{A}$ phase at elevated temperatures, this smectic phase is also fluorescent, as long as the trans geometry of the azobenzene unit is retained. Upon photoisomerization, conversion to the cis geometry disrupts the chromophore orientation, resulting in the loss of mesogenicity.

While the fluorescence emission of AzoG1-AzoG3 at room temperature and AzoGo at elevated temperature is a consequence of the J-aggregate formation, the photoisomerization studies in thin solid films indicate that there also exist aggregates of the H-type, as evidenced from the appearance of the $320 \mathrm{~nm}$ main absorption band in the photolyzed films, as opposed to the $350 \mathrm{~nm}$ band in the unphotolyzed films. These H-type aggregates do not undergo facile trans-cis photoisomerization in the glassy state and thus the absorption becomes more pronounced as a result of depletion of the trans isomers of the monomer and J-aggregate on photolysis. Weener and Meijer ${ }^{[13 \mathrm{~g}]}$ have observed that photoisomerization of azobenzene is restricted in dendritic monolayers with a strong tendency to form $\mathrm{H}$-aggregates.

\section{Conclusion}

The synthesis and study of azobenzene-functionalized poly(alkyl aryl ether) dendrimers is an interesting extension of a number of previous studies on azobenzene-containing dendrimers. The major findings from our detailed studies are:

1) the dendritic architecture influences and promotes properties of azobenzene that are normally associated only with aggregates of azobenzene; 2) the anomalous solidstate fluorescence emission of the dendrimers AzoG1-AzoG3 at room temperature are characteristic, reflecting the optimum levels of inherent structural features that facilitate aggregate formation; and 3) the liquid crystalline AzoM is also fluorescent in its liquid crystalline and isotropic phases, provided it is maintained in its trans geometry.

In line with a number of previous reports, the solutionphase properties are unexceptional in that the azobenzene units are independent of one another in spite of their clustering at the peripheries of dendrimers.

\section{Experimental Section}

General methods: Chemicals were purchased from commercial sources and were used without further purification. $\mathrm{K}_{2} \mathrm{CO}_{3}$ (AR grade) was dried at $120^{\circ} \mathrm{C}$ for $24 \mathrm{~h}$ before being used. Solvents were dried and distilled according to literature procedures. ${ }^{[17]}$ Analytical TLC was performed on commercial Merck plates coated with silica gel $\mathrm{GF}_{254}(0.25 \mathrm{~mm})$. Silica gel (100-200 mesh) was used for column chromatography. Melting points are uncorrected. Gel permeation chromatography (GPC) was carried out on a Phenogel $(500 \AA)$ semipreparative column $(300 \times 7.80 \mathrm{~mm})$ attached to a high-performance liquid chromatography system fitted with a differential refractive index (RI) detector; THF was used as the eluent. Matrix-assisted laser desorption ionization-time-of-flight mass spectrometry (MALDI-TOF MS) was performed using either gentisic acid or transindole acrylic acid as the matrix on a Kratos instrument. Microanalyses were performed on an automated Carlo-Erba $\mathrm{C}, \mathrm{H}, \mathrm{N}$ analyzer. ${ }^{1} \mathrm{H}$ and ${ }^{13} \mathrm{C}$ NMR spectral analyses were performed on a $300 \mathrm{MHz}$ and $75 \mathrm{MHz}$ Jeol spectrometer, respectively, with residual solvent signal acting as the internal standard. The following abbreviations were used to explain the multiplicities: s, singlet; d, doublet; t, triplet; m, multiplet; band, several overlapping signals; br, broad.

AzoM: $\mathrm{K}_{2} \mathrm{CO}_{3}(0.54 \mathrm{~g}, 3.94 \mathrm{mmol})$ and $18-\mathrm{C}-6$ (cat.) were added to a stirred solution of 1,5-dibromopentane $(2.71 \mathrm{~g}, 11.8 \mathrm{mmol})$ in $\mathrm{Me}_{2} \mathrm{CO}$ $(20 \mathrm{~mL}), 4-[(4-b u t y l p h e n y l) a z o] p h e n o l ~(1.0 \mathrm{~g}, 3.94 \mathrm{mmol})$, and the mixture was refluxed for $7 \mathrm{~h}$. The solvents were removed in vacuo and the resulting residue was dissolved in $\mathrm{CH}_{2} \mathrm{Cl}_{2}$, washed with water and brine, and dried $\left(\mathrm{Na}_{2} \mathrm{SO}_{4}\right)$, concentrated, and purified $\left(\mathrm{SiO}_{2}\right.$, hexane/EtOAc 95:5) to afford AzoM as an orange solid (1.43 g, 90\%). $R_{\mathrm{f}}=0.43$ (hexane/EtOAc 95:5); m.p. $68-70{ }^{\circ} \mathrm{C} ;{ }^{1} \mathrm{H}$ NMR (300 $\left.\mathrm{MHz}, \mathrm{CDCl}_{3}\right): \delta=$ $0.94(\mathrm{t}, J=7.8 \mathrm{~Hz}, 3 \mathrm{H}), 1.38(\mathrm{~m}, J=7.5 \mathrm{~Hz}, 2 \mathrm{H}), 1.64(\mathrm{~m}, 4 \mathrm{H}), 1.85$ $(\mathrm{m}, 2 \mathrm{H}), 1.95(\mathrm{~m}, 2 \mathrm{H}), 2.68(\mathrm{t}, J=7.5 \mathrm{~Hz}, 2 \mathrm{H}), 3.46(\mathrm{t}, J=6.6 \mathrm{~Hz}$, $2 \mathrm{H}), 4.05(\mathrm{t}, J=6.6 \mathrm{~Hz}, 2 \mathrm{H}), 6.99(\mathrm{~d}, J=8.7 \mathrm{~Hz}, 2 \mathrm{H}), 7.30(\mathrm{~d}, J=$ $8.2 \mathrm{~Hz}, 2 \mathrm{H}), 7.80(\mathrm{~d}, J=8.2 \mathrm{~Hz}, 2 \mathrm{H}), 7.89 \mathrm{ppm}(\mathrm{d}, J=8.7 \mathrm{~Hz}, 2 \mathrm{H}) ;{ }^{13} \mathrm{C}$ NMR (75.5 MHz, $\left.\mathrm{CDCl}_{3}\right): \delta=13.9,22.3,24.8,28.4,32.4,33.5,33.6,35.5$, 67.8, 114.6, 122.5, 124.5, 129.0, 145.8, 147.0, 151.0, $161.2 \mathrm{ppm} ; \mathrm{UV} / \mathrm{Vis}$ $(\mathrm{PhMe}): \lambda_{\max }=352 \mathrm{~nm}$; EI-MS: $m / z: 403[M]^{+}, 405[M+2]^{+}$; elemental analysis calcd for $\mathrm{C}_{21} \mathrm{H}_{27} \mathrm{BrN}_{2} \mathrm{O}$ : C 62.66, $\mathrm{H}$ 6.76, N 6.96; found: C 62.34, H 6.75, N 6.64.

AzoG0: A mixture of tris-5-bromopentyl phloroglucinol ${ }^{[8]}(0.10 \mathrm{~g}$, $0.17 \mathrm{mmol}), 4$-[(4-butylphenyl)azo]phenol $(0.22 \mathrm{~g}, 0.87 \mathrm{mmol}), \mathrm{K}_{2} \mathrm{CO}_{3}$ $(0.10 \mathrm{~g}, 0.72 \mathrm{mmol})$, and $18-\mathrm{C}-6$ (cat.) in $\mathrm{MeCN}(20 \mathrm{~mL})$ was refluxed for $17 \mathrm{~h}$, filtered, and the solvents were removed in vacuo. Flash chromatography of the resulting residue $\left(\mathrm{SiO}_{2}, \mathrm{PhMe} /\right.$ EtOAc 98:2) afforded AzoGo as an orange solid $(0.162 \mathrm{~g}, 85 \%) . R_{\mathrm{f}}=0.80$ (PhMe/EtOAc 98:2); m.p. $70-73{ }^{\circ} \mathrm{C} ;{ }^{1} \mathrm{H}$ NMR $\left(300 \mathrm{MHz}, \mathrm{CDCl}_{3}\right): \delta=0.94(\mathrm{t}, J=7.5 \mathrm{~Hz}, 9 \mathrm{H})$, $1.38(\mathrm{~m}, J=7.2 \mathrm{~Hz}, 6 \mathrm{H}), 1.63(\mathrm{~m}, 12 \mathrm{H}), 1.86(\mathrm{~m}, 12 \mathrm{H}), 2.67(\mathrm{t}, J=$ $7.2 \mathrm{~Hz}, 6 \mathrm{H}), 3.96(\mathrm{t}, J=6.3 \mathrm{~Hz}, 6 \mathrm{H}), 4.06(\mathrm{t}, J=6.3 \mathrm{~Hz}, 6 \mathrm{H}), 6.08(\mathrm{~s}$, $3 \mathrm{H}), 6.99(\mathrm{~d}, J=9.0 \mathrm{~Hz}, 6 \mathrm{H}), 7.30(\mathrm{~d}, J=8.1 \mathrm{~Hz}, 6 \mathrm{H}), 7.79(\mathrm{~d}, J=$ $8.1 \mathrm{~Hz}, 6 \mathrm{H}), 7.89 \mathrm{ppm}(\mathrm{d}, J=9.0 \mathrm{~Hz}, 6 \mathrm{H}) ;{ }^{13} \mathrm{C} \mathrm{NMR}(75.5 \mathrm{MHz}$, $\left.\mathrm{CDCl}_{3}\right): \delta=13.9,22.3,22.7,28.9,33.5,35.5,67.8,68.1,93.9,114.7,122.5$, 124.6, 129.0, 145.8, 147.0, 151.0, 160.9, $161.4 \mathrm{ppm}$; UV/Vis (PhMe): $\lambda_{\max }$ $=350 \mathrm{~nm}$; MALDI-TOF MS: $m / z: 1094.4[M+\mathrm{H}]^{+}$; elemental analysis calcd for $\mathrm{C}_{69} \mathrm{H}_{84} \mathrm{~N}_{6} \mathrm{O}_{6}$ : C 75.79, H 7.74, N 7.68; found: C 75.73, H 8.22, N 6.86 .

AzoG1: A mixture of G1- $(\mathrm{OH})_{6}^{\left[{ }^{[8]}\right.}(0.040 \mathrm{~g}, 0.06 \mathrm{mmol}), 4-[(4-$ butylphenyl)azo]phenol $(0.228 \mathrm{~g}, \quad 0.56 \mathrm{mmol}), \quad \mathrm{K}_{2} \mathrm{CO}_{3} \quad(0.080 \mathrm{~g}, \quad 0.56 \mathrm{mmol}), \quad$ and [18]crown-6 (cat.) in MeCN (12 mL) was refluxed for $42 \mathrm{~h}$, filtered, and the solvents were removed in vacuo. Flash chromatography of the crude residue $\left(\mathrm{SiO}_{2}, \mathrm{PhMe} /\right.$ EtOAc 98:2) afforded AZoG1 as an orange, low- 
melting solid $(0.12 \mathrm{~g}, 80 \%) . R_{\mathrm{f}}=0.53(\mathrm{PhMe} / \mathrm{EtOAc} 98: 2)$; m.p. 40 $42{ }^{\circ} \mathrm{C} ;{ }^{1} \mathrm{H}$ NMR $\left(300 \mathrm{MHz}, \mathrm{CDCl}_{3}\right): \delta=0.93(\mathrm{t}, J=7.2 \mathrm{~Hz}, 18 \mathrm{H}), 1.37$ $(\mathrm{m}, J=7.5 \mathrm{~Hz}, 12 \mathrm{H}), 1.61(\mathrm{br}, 30 \mathrm{H}), 1.83(\mathrm{br}, 36 \mathrm{H}), 2.66(\mathrm{t}, J=7.5 \mathrm{~Hz}$, $12 \mathrm{H}), 3.93(\mathrm{br}, 24 \mathrm{H}), 4.03(\mathrm{t}, J=6.0 \mathrm{~Hz}, 12 \mathrm{H}), 6.06(\mathrm{~s}, 12 \mathrm{H}), 6.97(\mathrm{~d}, J$ $=7.8 \mathrm{~Hz}, 12 \mathrm{H}), 7.28(\mathrm{~d}, J=7.5 \mathrm{~Hz}, 12 \mathrm{H}), 7.78(\mathrm{~d}, J=7.5 \mathrm{~Hz}, 12 \mathrm{H})$, $7.87 \mathrm{ppm}(\mathrm{d}, J=7.8 \mathrm{~Hz}, 12 \mathrm{H}) ;{ }^{13} \mathrm{C}$ NMR $\left(75.5 \mathrm{MHz}, \mathrm{CDCl}_{3}\right): \delta=13.9$, 22.3, 22.7, 28.9, 29.0, 33.5, 35.5, 67.7, 67.8, 68.1, 93.9, 114.7, 122.5, 124.5, $129.0,145.8,147.0,151.0,160.9,161.3 \mathrm{ppm}$; UV/Vis $(\mathrm{PhMe}): \lambda_{\max }=$ $352 \mathrm{~nm}$; MALDI-TOF MS: $\mathrm{m} / z: 2643.1[\mathrm{M}]^{+}$; elemental analysis calcd for $\mathrm{C}_{165} \mathrm{H}_{204} \mathrm{~N}_{12} \mathrm{O}_{18}$ : C 74.97, H 7.78, N 6.36; found: C 75.16, H 8.02, N 6.11 .

AzoG2: A mixture of $\mathrm{G} 2-(\mathrm{OH})_{12}{ }^{[8]}(0.14 \mathrm{~g}, 0.075 \mathrm{mmol}), 4-[$ (4-butylphenyl)azo]phenol $(0.47 \mathrm{~g}, 1.17 \mathrm{mmol})$, and $\mathrm{Cs}_{2} \mathrm{CO}_{3}(0.38 \mathrm{~g}, 1.17 \mathrm{mmol})$ in DMF $(8 \mathrm{~mL})$ was stirred over a period of nine days. The reaction mixture was then filtered, the filtrate diluted in $\mathrm{CH}_{2} \mathrm{Cl}_{2}$, washed with water and brine, dried, and concentrated. Flash chromatographic purification $\left(\mathrm{SiO}_{2}\right.$, $\mathrm{PhMe} /$ EtOAc 99:1) of the resulting product afforded AzoG2 as an orange, glassy solid $(0.26 \mathrm{~g}, 61 \%) . R_{\mathrm{f}}=0.33(\mathrm{PhMe} / \mathrm{EtOAc} 98: 2) ;{ }^{1} \mathrm{H}$ NMR $\left(300 \mathrm{MHz}, \mathrm{CDCl}_{3}\right): \delta=0.93(\mathrm{t}, J=7.2 \mathrm{~Hz}, 36 \mathrm{H}), 1.34(\mathrm{~m}, J=$ $7.2 \mathrm{~Hz}, 24 \mathrm{H}), 1.61(\mathrm{br}, 66 \mathrm{H}), 1.83(\mathrm{br}, 84 \mathrm{H}), 2.66(\mathrm{t}, J=7.2 \mathrm{~Hz}, 24 \mathrm{H})$, $3.92(\mathrm{br}, 60 \mathrm{H}), 4.02(\mathrm{brt}, J=6.3 \mathrm{~Hz}, 24 \mathrm{H}), 6.06(\mathrm{~s}, 30 \mathrm{H}), 6.97(\mathrm{~d}, J=$ $9.0 \mathrm{~Hz}, 24 \mathrm{H}), 7.28(\mathrm{~d}, J=8.4 \mathrm{~Hz}, 24 \mathrm{H}), 7.79(\mathrm{~d}, J=8.4 \mathrm{~Hz}, 24 \mathrm{H})$, $7.87 \mathrm{ppm}(\mathrm{d}, J=9.0 \mathrm{~Hz}, 24 \mathrm{H}) ;{ }^{13} \mathrm{C}$ NMR $\left(75.5 \mathrm{MHz}, \mathrm{CDCl}_{3}\right): \delta=13.9$, 22.3 , 22.7, 28.9, 29.0, 33.4, 35.5, 67.7, 68.0, 93.8, 114.6, 122.5, 124.5, 129.0, 145.7, 147.0, 151.0, 160.9, $161.3 \mathrm{ppm}$; UV/Vis $(\mathrm{PhMe}): \lambda_{\max }=352 \mathrm{~nm}$; MALDI-TOF MS: $\mathrm{m} / \mathrm{z}: 5738.9[\mathrm{M}]^{+}$; elemental analysis cacld for $\mathrm{C}_{357} \mathrm{H}_{444} \mathrm{~N}_{24} \mathrm{O}_{42}$ : C 74.66, H 7.79, N 5.85; found: C 75.24., H 8.07, N 5.70. AzoG3: A mixture of G3- $(\mathrm{OH})_{24}{ }^{[8]}(0.07 \mathrm{~g}, 0.017 \mathrm{mmol}), 4-[(4-$ butylphenyl)azo]phenol $(0.23 \mathrm{~g}, 0.56 \mathrm{mmol})$, and $\mathrm{Cs}_{2} \mathrm{CO}_{3}(0.18 \mathrm{~g}, 0.56 \mathrm{mmol})$ in DMF $(5 \mathrm{~mL})$ was stirred over a period of nine days. The reaction mixture was then filtered, the was filtrate diluted in $\mathrm{CH}_{2} \mathrm{Cl}_{2}$ and washed with water and brine, dried, and concentrated. Flash chromatographic purification $\left(\mathrm{SiO}_{2}, \mathrm{PhMe} / \mathrm{EtOAc}\right.$ 98:2) of the resulting product afforded AZoG3 as an orange, glassy solid $(0.08 \mathrm{~g}, 40 \%) \cdot R_{\mathrm{f}}=0.58(\mathrm{PhMe} /$ EtOAc 95:5); ${ }^{1} \mathrm{H}$ NMR $\left(300 \mathrm{MHz}, \mathrm{CDCl}_{3}\right): \delta=0.93(\mathrm{t}, J=7.2 \mathrm{~Hz}$, $72 \mathrm{H}), 1.36(\mathrm{~m}, J=7.5 \mathrm{~Hz}, 48 \mathrm{H}), 1.62(\mathrm{br}, 138 \mathrm{H}), 1.81(\mathrm{br}, 180 \mathrm{H}), 2.65$ $(\mathrm{t}, J=7.2 \mathrm{~Hz}, 48 \mathrm{H}), 3.90(\mathrm{br}, 132 \mathrm{H}), 4.01(\mathrm{br}, 48 \mathrm{H}), 6.04(\mathrm{br}, 66 \mathrm{H})$, $6.96(\mathrm{~d}, J=8.4 \mathrm{~Hz}, 48 \mathrm{H}), 7.28(\mathrm{~d}, J=8.0 \mathrm{~Hz}, 48 \mathrm{H}), 7.78(\mathrm{~d}, J=$ $8.0 \mathrm{~Hz}, 48 \mathrm{H}), 7.87 \mathrm{ppm}(\mathrm{d}, J=8.4 \mathrm{~Hz}, 48 \mathrm{H}) ;{ }^{13} \mathrm{C} \mathrm{NMR}(75.5 \mathrm{MHz}$, $\left.\mathrm{CDCl}_{3}\right): \delta=13.9,22.3,22.7,28.9,33.4,35.5,67.7,68.0,93.8,114.6,122.5$, 124.5, 129.0, 145.7, 146.9, 150.9, 160.8, 161.3 ppm; UV/Vis (PhMe): $\lambda_{\max }$ $=352 \mathrm{~nm}$; elemental analysis calcd for $\mathrm{C}_{741} \mathrm{H}_{924} \mathrm{~N}_{48} \mathrm{O}_{90}$ : C 74.52, H 7.80, N 5.63; found: C 73.90, H 7.75, N 5.23.

Instrumentation: Phase transitions were observed using a Nikon HFX 35A Optiphot-2 polarized light optical microscope, equipped with a Linkam THMS 600 heating and freezing stage connected to a Linkam TP92 temperature programmer. DSC analyses were preformed under air, using a DuPont DSC 2010 differential scanning calorimeter attached to a Thermal Analyst 2100 data station. Absorption spectra were recorded on a Shimadzu 3101PC UV/Vis-NIR spectrophotometer. Steady-state photolysis was carried out using a $200 \mathrm{~W}$ high-pressure mercury lamp, in combination with a $360 \mathrm{~nm}$ Oriel bandpass filter. Laser photolysis was carried out using the third harmonic $(355 \mathrm{~nm}, 5 \mathrm{~mJ}$ per pulse, pulse width $10 \mathrm{~ns})$ of a Quanta Ray GCR-12 Nd:YAG laser. The excitation and emission spectra were measured on a SPEX Fluorolog F112X spectrofluorimeter.

\section{Acknowledgement}

Financial support from Council of Scientific and Industrial Research, New Delhi (N.J.) and Defense Research and Development Organization, New Delhi (N.J. and S.D.) is gratefully acknowledged. J.N. and R.D. acknowledge the Council of Scientific and Industrial Research, New Delhi, for research fellowships. This is contribution no. RRLT-PPD-172 from the Regional Research Laboratory, Trivandrum.
[1] Reviews, for example: a) D. A. Tomalia, A. M. Naylor, W. A. Goddard III, Angew. Chem. 1990, 102, 119; Angew. Chem. Int. Ed. Engl. 1990, 29, 138; b) F. Zeng, S. C. Zimmerman, Chem. Rev. 1997, 97 1681; c) H. F. Chow, T. K. K. Mong, M. F. Nongrum, C. W. Wan, Tetrahedron 1998, 54, 8543; d) G. R. Newkome, F. Vögtle, C. N. Moorefield, Dendrimers and Dendrons, Wiley-VCH, Weinheim, 2001; e) Dendrimers and Other Dendritic Polymers (Eds.: J. M. J. Fréchet, D. A. Tomalia), Wiley, Chichester, 2001; f) O. Villavicencio, D. V. McGrath, in Advances in Dendritic Macromolecules, (Ed.: G. R. Newkome), Elsevier Sciences Ltd., Oxford, pp. 1-44, 2002.

[2] a) A. Adronov, J. M. J. Fréchet, Chem. Commun. 2000, 1701; b) V. Balzani, S. Campagna, G. Denti, A. Juris, S. Serroni, M. Venturi, Acc. Chem. Res. 1997, 30, 26; c) J. S. Moore, Acc. Chem. Res. 1997, 30, 402; d) D.-L. Jiang, T. Aida, J. Am. Chem. Soc. 1998, 120, 10895; e) F. Li, S. I. Yang, Y. Ciringh, J. Seth, C. H. Martin III, D. L. Singh, D. Kim, R. R. Birge, D. F. Bocian, D. Holten, J. S. Lindsey, J. Am. Chem. Soc. 1998, 120, 10001; f) G. M. Stewart, M. A. Fox, J. Am. Chem. Soc. 1996, 118, 4354; g) S. L. Gilat, A. Adronov, J. M. J. Fréchet, Angew. Chem. Int. Ed. 1999, 38, 1422; h) M.-H. Xu, J. Lin, Q.S. Hu, L. Pu, J. Am. Chem. Soc. 2002, 124, 14239; i) S. Wang, W. J. Oldham Jr. , R. A. Hudack Jr. , G. C. Bazan, J. Am. Chem. Soc. 2000, 122, 5695; j) R. G. Ispasoiu, L. Balogh, O. P. Varnavski, D. A. Tomalia, T. Goodson III, J. Am. Chem. Soc. 2000, 122, 11005; k) G. De Belder, G. Schweitzer, S. Jordens, M. Lor, S. Mitra, J. Hofkens, S. De Feyter, M. Van der Auweraer, A. Herrmann, T. Weil, K. Müllen, F. C. De Schryver, ChemPhysChem 2001, 2, 49.

[3] R-M. Sebastian, J-C. Blais, A-M. Caminade, J-P. Majoral, Chem. Eur. J. 2002, 8, 2172.

[4] K. Tsuda, G. C. Dol, T. Gensch, J. Hofkens, L. Latterini, J. W. Weener, E. W. Meijer, F. C. De Schryver, J. Am. Chem. Soc. 2000, 122,3445 .

[5] a) A. Archut, G. C. Azzellini, V. Balzani, L. De Cola, F. Vögtle, J. Am. Chem. Soc. 1998, 120, 12187; b) A. Archut, F. Vögtle, L. De Cola, G. C. Azzellini, V. Balzani, P. S. Ramanujam, R. H. Berg, Chem. Eur. J. 1998, 4, 699.

[6] D. Patton, M.-K. Park, S. Wang, R. C. Advincula, Langmuir 2002, $18,1688$.

[7] a) D. M. Junge, D. V. McGrath, Chem. Commun. 1997, 857; b) D. M. Junge, D. V. McGrath, J. Am. Chem. Soc. 1999, 121, 4912; c) S. Li, D. V. McGrath, J. Am. Chem. Soc. 2000, 122, 6795; d) S. Yokoyama, T. Nakahama, A. Otomo, S. Mashiko, J. Am. Chem. Soc. 2000, 122, 3174; e) A. Yu. Bobrovsky, A. A. Pakhomov, X. M. Zhu, N. I. Boiko, V. P. Shibaev, J. Polym. Sci. Part. A 2001, 43, 431; f) A. Yu. Bobrovsky, A. A. Pakhomov, X.-M. Zhu, N. I. Boiko, V. P. Shibaev, J. Stumpe, J. Phys. Chem. B 2002, 106, 540; g) D. Grebel-Koehler, D. Liu, S. DeFeyter, V. Enkelmann, T. Weil, C. Engels, C. Samyn, K. Müllen, F. C. De Schryver, Macromolecules 2003, 36, 578; h) H. C. Yoon, H. K. Shin, C. Kim, Y. S. Kwon, Synt. Met. 2003, 137, 1427; i) J. M. Kim, H. K. Shin, E. Park, C. K. Kim, Y.-S. Kwon, Mol. Cryst. Liq. Cryst. 2002, 377, 197; j) S. Ghosh, A. K. Banthia, Tetrahedron Lett. 2001, 42, 501.

[8] J. Nithyanandhan, N. Jayaraman, J. Org. Chem. 2002, 67, 6282.

[9] H. Rau, in Photochromism (Eds.: H. Dürr, H. Bouas-Laurent), Elsevier, Amsterdam 1990, Chapter 4.

[10] E. G. McRae, M. Kasha in Physical Processes in Radiation Biology (Eds.: L. Augenstein, R. Mason, B. Roseberg), Academic Press, New York, 1964, p. 23.

[11] a) T. Kunitake, Y. Okahata, M. Shimomura, S.-I. Yasunami, K. Takarabe, J. Am. Chem. Soc. 1981, 103, 5401; b) M. Shimomura, T. Kunitake, J. Am. Chem. Soc. 1987, 109, 5175; c) R. A. Moss, W. Jiang, Langmuir 1995, 11, 4217.

[12] a) X. Song, J. Perlstein, D. G. Whitten, J. Am. Chem. Soc. 1997, 119, 9144; b) D.-M. Shin, K. S. Schanze, D. G. Whitten, J. Am. Chem. Soc. 1989, 111, 8494.

[13] a) T. Seki, H. Sekizawa, R. Fukuda, T. Tamaki, M. Yokoi, K. Ichimura, Polym. J. 1996, 28, 613; b) T. Seki, J. Kojima, K. Ichimura, Macromolecules 2000, 33, 2709; c) M. Matsumoto, D. Miyazaki, M. Tanaka, R. Azumi, E. Manda, Y. Kondo, N. Yoshino, H. Tachibana, J. Am. Chem. Soc. 1998, 120, 1479; d) S. Dante, R. Advincula, C. W. Frank, P. Stroeve, Langmuir 1999, 15, 193; e) K. Mathauer, T. Vahlenkamp, C. W. Frank, G. Wagner, Langmuir 1993, 9, 1582; f) A. Si- 
dorenko, C. Houphouet-Boigny, O. Villavicencio, M. Hashemzadeh, D. V. McGrath, V. V. Tsukruk, Langmuir 2000, 16, 10569; g) J.-W. Weener, E. W. Meijer, Adv. Mater. 2000, 12, 741; h) J. Heesemann, J. Am. Chem. Soc. 1980, 102, 2167.

[14] a) J. P. Otruba III, R. G. Weiss, J. Org. Chem. 1983, 48, 3448; b) J. Azuma, A. Shishido, T. Ikeda, N. Tamai, Mol. Cryst. Liq. Cryst. 1998, 314,83

[15] a) P. D. Wildes, J. G. Pacifici, G. Irick Jr. , D. G. Whitten, J. Am. Chem. Soc. 1971, 93, 2004; b) E. V. Brown, G. R. Granneman, J. Am. Chem. Soc. 1975, 97, 621; c) T. Asano, T. Okada, S. Shinkai, K.
Shigematsu, Y. Kusano, O. Manabe, J. Am. Chem. Soc. 1981, 103, 5161; d) C. Ruslim, K. Ichimura, J. Mater. Chem. 2000, 10, 2704.

[16] a) T. Ikeda, O. Tsutsumi, Science 1995, 268, 1873; b) T. Ikeda, A. Kanazawa, Molecular Switches, Wiley-VCH, Weinheim, 2001; c) V. A. Mallia, M. George, S. Das, Chem. Mater. 1999, 11, 207; d) R. Davis, V. A. Mallia, S. Das, Chem. Mater. 2003, 15, 1057.

[17] D. D. Perrin, W. L. F. Armarego, Purification of Laboratory Chemicals, 3rd ed., Pergamon, Oxford, 1988.

Received: July 2, 2003 Revised: September 15, 2003 [F 5297] 